\title{
Education with Human Touch
}

\section{Baral G}

Chief Editor, NJOG

Received: 10-Apr-2017; Accepted: 30-May-2017

\begin{abstract}
Obstetrics and gynecology education deals with the physiological processes and pathology equally. Three competency domains such as knowledge, skills and attitudes are equally important. Scientific and ethical clinical practice survives only with the education that has human touch.
\end{abstract}

Keywords: competency, education, skills

DOI: 10.3126/njog.v12i2.19940

Medical profession is a business of a society that heals sorrows and promotes to survive at the best. Medical science is incomplete without art meaning that both knowledge and skills are required. Learning obstetrics and gynecology will be incomplete by didactic teaching or observership only; neither it would be complete by merely reading text nor working mechanically without theoretical back up. It requires both knowledge and skill. Proficiency and competency on the subject matter are the two pillars of successful obgyn (obstetrician and gynecologist) practitioner and teacher. Skill acquisition requires task based learning with evaluation by competency level. Assigning service provider without competency evaluation will not work in real world and in fact it is assigning risk to the people. All three competency domains namely knowledge, skills and attitudes have to be blended in clinical science and practice. ${ }^{1}$ It would be more relevant in the field of obstetrics and gynecology as there are more physiological processes of reproduction to deal by obgyn specialist.

Education model depends on the real need. Our real need will be addressed by quality product but politicized or virtual need will be fulfilled by quantity product that is assigning risk to the society and demoralizing individual in front of society. Simulation learning is a part of skill learning but not the sole learning method. This is the preliminary methodical step. Non-touch learning never provides human touch and value. ${ }^{2}$ Thus, it has to go either simultaneously or in succession for complete learning.

\section{CORRESPONDENCE}

Prof. Gehanath Baral

Chief Editor, NJOG

gehanath@gmail.com

njogeditor@gmail.com
Observership is useful and beneficial in secondary learning process for which basic proficiency and competency is required for full benefit. Training should also follow a standardized method for tracking and benchmarking the quality of medical education scholarship in obstetrics and gynecology. ${ }^{3}$

Building knowledge using validated techniques, developing skills by appropriate methodology and shaping attitudes with value clarification exercises are the key elements in value based education and training. Humanistic training followed by cognitive apprenticeship would provide easy to translate skill acquisition. ${ }^{1}$ Such educational principles would provide skills to trainee to be rapidly acceptable by target clients in real world. Every skill should be evaluated by a standard tool with respect to respective clinical task but skills without adequate knowledge or scientific information cannot succeed in ever developing medical science and arts.

\section{CONCLUSIONS}

Present day education in obstetrics and gynecology warrants proficiency as well as competency based training. More human touch is required to deal with physiological events of obstetrics and pathological processes. Thus an easy to translate skill acquisition is to be assured and practiced.

\section{REFERENCES}

1. Blueston J, Fowler R, Johnson P, Smith J, editors. Clinical training skills course - reference manual. Baltimore: Jhpiego Corporation. 2010.

2. Young AE. Value-based medical education in obstetrics and gynecology - a paradigm shift. Obstet Gynecol. 2017;130(4):684-5

3. Smith RP, Learman LA. A plea for mersqi. The medical education research study quality instrument. Obstet Gynecol. 2017; 130:686-90 